\title{
ICMAT2001 in Singapore Demonstrates Driving Forces in Advanced Materials
}

The Materials Research SocietySingapore organized the International Conference on Materials for Advanced Technologies (ICMAT2001) as a part of its effort to serve the materials community and to reach out to the region and beyond. The conference was held at the Singapore International Convention and Exhibition Center July 1-6. About 1400 members of the international scientific and materials research community representing 42 countries attended, including 300 researchers and graduate students from Singapore. More than 50 vendors displayed equipment and products at the accompanying exhibition. Students from the National University of Singapore (NUS) provided musical entertainment at the conference banquet held at the RitzCarlton Hotel.

The conference opened on July 2 with welcome addresses by the chair, B.V.R. Chowdari (NUS). He spoke about the miniaturization and popularization of electronic products in our daily lives, such as personal computers and cellular phones, as driving the development of new materials and devices. Materials science, the basis for all such advances, he said, is enjoying new developments almost every day. Conference co-chair Albert F. Yee (Institute of Materials Research and Engineering, IMRE) added his welcome to the participants and invited them to visit IMRE and establish scientific links with its staff.

Shih Choon Fong, principal advisor for the conference and also the vice chancellor of NUS, welcomed the participants at the formal inauguration, where he emphasized the importance of materials research. He noted that advanced materials are enablers for the four pillars of Singapore's manufacturing economy: electronics, chemicals, engineering, and the life sciences. He also said that NUS is committed to nurturing talent and entrepreneurship in these areas and encouraged the younger generation to take full advantage of the deliberations at the conference. The guest of honor at this ceremony, Tony Tan, deputy prime minister and minister for defense of the government of Singapore, remarked that the organization of this conference in Singapore is very timely and congratulated MRS-Singapore for its efforts. He conveyed best wishes for the ICMAT2001.

During each of the five days, the earlymorning sessions were devoted to plenary lectures in which noted experts presented review talks and attempted to predict

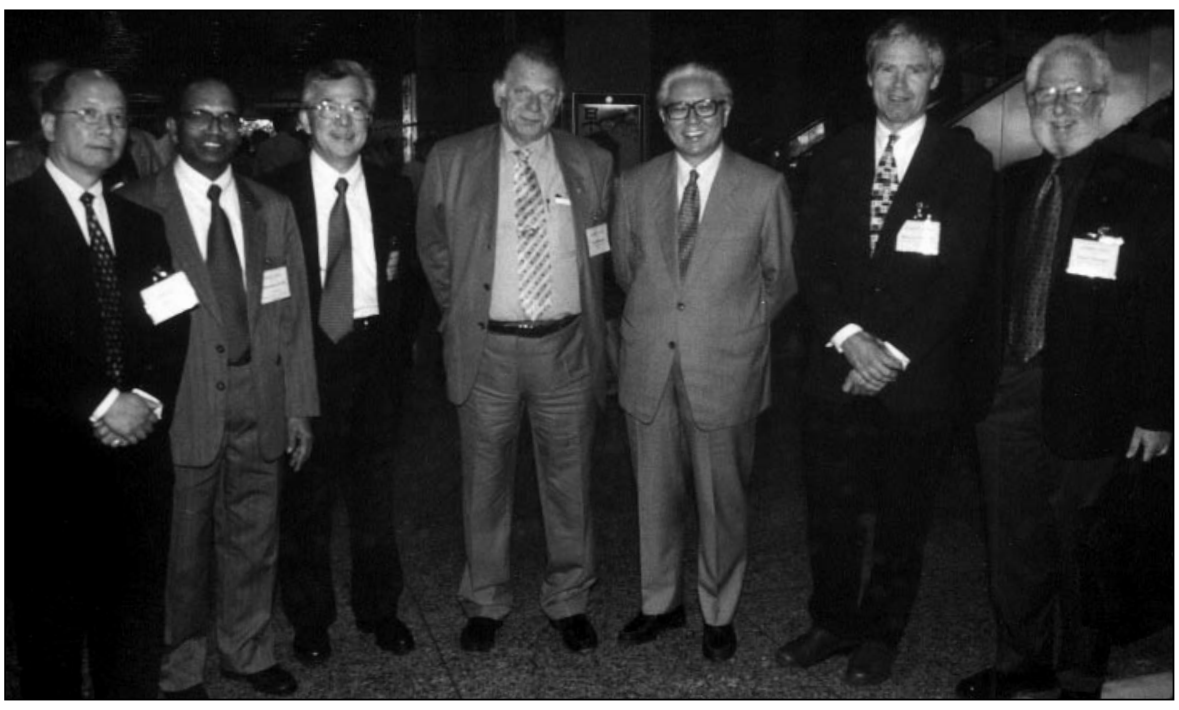

Participating in ICMAT2001 in Singapore are (left to right): Albert F. Yee, co-chair; B.V.R. Chowdari, chair; C.F. Shih, vice chancellor of the National University of Singapore; Nobel Laureate Z.A. Alferov, Russia; guest of honor Tony Tan, deputy prime minister and minister for defense, Singapore; Nobel Laureate Horst L. Stormer, USA; and Nobel Laureate Alan J. Heeger, USA.

future directions in their fields for the first decade of the new millennium. There were also public addresses in the evening for conference attendees, students, and the public. These included talks by four Nobel Laureates: Z.I. Alferov (Ioffe Institute, St. Petersburg, Russia), who spoke on the subject of semiconductor heterostructures; J.G. Bednorz (IBM Zurich Research Laboratories, Ruschlikon, Switzerland) on perovskites; Alan J. Heeger (University of California-Santa Barbara) on plastic electronics; and Horst L. Stormer (Columbia University and Bell Labs) on physics in the communications industry.

In addition to these four public lectures, there was a short video presentation by Nobel Laureate Jean-Marie Lehn (Université de Strasbourg/Collège de France) on "From Matter to Life-Chemistry?!" and a lecture on tissue engineering by Charles Vacanti (University of Massachusetts Medical Center). Also addressing plenary sessions were David Williams (Lehigh University, Bethlehem, Penn.) on research and education in the Internet age, Alexander A. Chernov (NASA's Marshall Space Flight Center) on crystallization science, Shuji Nakamura (University of CaliforniaSanta Barbara) on light-emitting diodes, Yoshio Nishi (Sony Corporation, Japan) on lithium-ion polymer batteries, and C.N.R. Rao (Jawaharlal Nehru Center for Advanced Scientific Research, Bangalore,
India) on chemical design of new materials.

The materials areas that were covered included ionic and mixed conducting materials for advanced batteries and fuelcell applications, biomaterials for tissue engineering, ceramics, magnetic materials for data storage, diamond-like carbon, polymers and composites, environmental materials, nanoscale materials and technologies, semiconducting materials for optoelectronics and high-frequency electronics applications, and ceramic superconductors for quantum devices and power transmission. Specialized aspects of crystallization and interfacial processes, thin films, modeling, microelectronics packaging, and materials education were also addressed. A few research highlights are presented here.

In Symposium A: Materials for Advanced Batteries and Fuel Cells, Li-ion batteries, which are now the preferred high energy-density rechargeable batteries for portable applications, were emphasized. New prospective anode materials based on cobalt oxides and nanoalloys such as $\mathrm{SnSb}, \mathrm{Cu}_{6} \mathrm{Sn}_{5}$, and InSb were discussed. Methods for performance improvement of $\mathrm{LiMn}_{2} \mathrm{O}_{4}$ and iron-based cathodes, namely, $\mathrm{LiFePO}_{4}$, received attention. New lithium solid electrolytes based on thio-lisicon, sulfide glasses and composites, and polymers were presented. Fuel cells based on solid oxides 
(SOFCs), proton-exchange membranes (PEMFCs), direct methanol (DMFCs), and molten carbonates (MCFCs) were discussed. Materials aspects, including the order-disorder transformation and gaspermeation behavior of the mixed oxides, received considerable attention. Emphasis was given to reduced-temperature operation of SOFCs using perovskite-type mixed oxides as cathode and electrolyte. Novel electrocatalysts (heat-treated metalloporphyrins) for DMFCs were presented. The proceedings of Symposium A will be published as a special issue of Solid State Ionics, an international journal.

In Symposium B: Biomaterials and Tissue Engineering, lead keynote speaker Vacanti gave a presentation on advances of tissue engineering, which inspired many students and researchers on the potential it holds for the future in health care and tissue/organ regeneration. The Journal of Materials Science E Engineering: $C$ and Tissue Engineering have agreed to publish the papers from this symposium.

Symposium C covered frontier areas of research in Novel and Advanced Ceramic Materials, namely, electroceramics, structural ceramics, ceramic composites, novel processing, thin films, functional ceramics, materials properties, and characterization. Recent developments in ceramic materials processing techniques (soft solution synthesis, mechanical activation, microwave processing, and nanoscale sol-gel preparations), future trends, and potential applications of functional materials (dielectric and ferroelectric) in microelectronics were some of the most prominent topics discussed. The papers will be published as a special issue of the International Journal: Materials Chemistry and Physics.

Symposium D: Crystallization and Interfacial Processes explored common themes in the growth of inorganic, organic, and macromolecular crystals and thin films produced through natural and synthetic processes. Latest developments and future trends in the sciences and technologies of crystal growth were presented. These were highlighted by the exciting advances in proteins and biomaterials crystallization; interface structures, surface morphologies, and kinetics by advanced technologies such as synchrotron radiation and atomic force microscopy; pattern formation; engineering of micro/nanostructure of complex systems and soft materials; kinetics of nucleation and colloidal crystallization; the effects of microgravity and magnetic field; and biomineralization. The presentations will be published as a special issue in the International Journal of Modern Physics B.

Symposium E: Advanced Data-Storage Materials provided a review of the funda- mental limits to magnetic recording and directions for materials research. The progress and prospects of "spintronics" wherein the electron spin degree of freedom, either alone or in combination with the electronic charge, can be employed for logic, memory, and photonics applications-were described as the next frontier.

In Symposium F: Diamond, Diamond-Like Carbon, and Related Materials, S. Prawer (Melbourne University, Australia) presented an invited talk on "Diamond Quantum Dots Fabricated by Ion Implantation" and a special review talk on "Quantum Computing." He predicted that diamond would become the "killer application" in quantum computing. Electron field emission continues to dominate much of the research effort in a number of laboratories due to the potential of carbon nanotubes as a cold cathode not only for field-emission display but also for e-beam lithography systems. The proceedings of this symposium will be published as a special issue of the International Journal of Modern Physics B.

In Symposium G, Plastic ElectronicsMaterials and Devices, new techniques such as maskless dye diffusion, sequential deposition and post-photoreaction, and novel interface engineering between electrode and organics were well received. It was felt that topics such as light emission, the role of energy transfer versus carrier trapping, and understanding the darkspot formation in organic light-emitting diodes through distribution approaches need to be studied in greater detail.

In Symposium H: Materials Science and Engineering Education in the New Millennium, two panel discussions (Resources for Materials Education and International Forum on Materials Education), with inputs from participants from various countries, ensured ample time for exchange of views, lively discussions, and planning future collaborations. Among the significant conclusions reached were that the university campus has a future; web access to teaching materials is highly useful to foster materials education (several sites are now freely available for the international community); interactive software, flexible learning programs, and educational modules with immersive virtual environments will be of great help; hands-on experiments and good demonstrations will do more for creating student interest than many dry lectures; the need exists for more outreach and perhaps more efforts to improve secondary school teaching for prospective undergraduate and graduate students; university departments and institutes in developed and developing countries are modifying and adopting their course curricula depending on the available expertise and the demand in terms of job opportunities in their industries; university-industry collaboration and training are of utmost importance for motivating students; and job satisfaction of the trained personnel clearly is not always to be equated with material success and high salaries. The proceedings of Symposium $\mathrm{H}$ will be published as a special issue of the Journal of Materials Education.

Symposium I: Advances in Environmental Materials was organized around two themes: pollution-control materials and environmentally preferred materials. Keynote lectures were given by $\mathrm{H}$. Matsuda (Nagoya University, Japan) on ash reuse, S. Komarneni (The Pennsylvania State University) on clay sorbents, H. Poellmann (University of Halle) on mineral reservoirs, F. Glasser (Massachusetts Institute of Technology) on waste form concretes, J. Ying (MIT) on nanoparticles, and S. Sivasanker (National Chemical Laboratory, India) on catalytic zeolites. The papers will be published as a two-volume monograph.

Symposium J: Packaging Materials and Processes for Microelectronics, Optoelectronics, MEMS, and Displays started with an overview of the reliability trends and challenges for integrated-circuit (IC) packaging in the new millennium. Some of the notable results presented in this symposium include the stability of the intermetallic compound (IMC) formed in solder reactions. It is related to the morphology: The scallop type is thermodynamically stable in wetting reactions, and the layer type is thermodynamically stable in solid-state aging reactions; microstructure and kinetics studies of $\mathrm{Pb}$-free solders $(\mathrm{Sn}-\mathrm{Ag}$; $\mathrm{Sn}-\mathrm{Ag}-\mathrm{Cu}$ ) in ball grid array IC packages with $\mathrm{Cu} / \mathrm{Ni} / \mathrm{Au}$ metallization showed different IMC formation at the interface- $-\mathrm{Ni}_{3} \mathrm{Sn}_{4}$ in $\mathrm{Sn}-\mathrm{Ag}$ and $\mathrm{Cu}-\mathrm{Sn}-\mathrm{Ni}$ in the $\mathrm{Sn}-\mathrm{Ag}-\mathrm{Cu}$ solder.

The theme of Symposium K was Advances in Polymers and Composites. In the area of polymers, recent developments on toughening mechanisms, fracture characterization, and polymer blends were highlighted. In the area of composites, sessions on nanocomposites and biocomposites proved very popular. It was proposed that the unique properties of nanocomposites, which are typically not shared with their conventional-composite counterparts, will offer new technology and business opportunities, while biocomposites have been recognized as one of the most promising materials for future applications in the life sciences and bioengineering. Presented papers will be published in special journal issues of Composites Science and Technology, 
and Plastics, Rubber, and Composites.

Symposium L: Modeling Materials and its Applications in Advanced Technologies covered materials modeling, experiments and simulations, $a b$ initio and atomistic theories, discrete systems, surface evolution, fracture mechanics, continuum mechanics, quantum mechanics, and industrial applications. Processes occurring during synthesis and drying of viscoelastic porous gels, phase transitions in binary and ternary solids, simulation of the development of stresses during densification of alumina, electronic-band structure calculations, electronic structure of interdiffused quantum dots, modeling of thermoelectric efficiency of materials with the clathrate structure, and simulation of structure and dynamics of super-cooled liquids of metallic glasses were discussed. Notable papers covered such topics as simulation of current-crowding in electromigration, matrix-BGA die cracking probability predictions, numerical studies of the effect of geometry on delaminations in small outline IC packages, dynamics of self-assembling nanostructures, and simulation and design optimization of a micropump.

Symposium M: Nanoscale Materials and Technologies covered the synthesis of nanomaterials composed of carbon nanotubes, oxide and nonoxide ceramics, metals and alloys, polymers, clays, and composites. The characterization of materials at the nanometer scale using scanning-probe microscopy, $\mathrm{x}$-rays, and transmission electron microscopy and the application of such materials for optical confinement, uses as sensors, and nanometer-scale devices were also presented. In particular, carbon nanotubes were discussed in detail, with demonstrated applications ranging from field-emission displays to tips in scanning probes, combinatorial chemistry synthesis, and uses in composites. Applications for other molecular systems included discussion on using self-assembled monolayers and small spatial confinement to cre- ate novel optical, electronic, and nonlinear effects. The spatial confinement could be created by actual manipulation of surface features using scanning probes and electron beams, or by more traditional synthetic routes. The proceedings are to be published in Materials Physics and Mechanics.

In Symposium N: Materials for Optoelectronics and High-Frequency Electronics, a novel method was proposed for the reduction of dislocation densities in the growth of $\mathrm{GaN}$ material. This was achieved by using an in situ technique for forming nano-sized holes in $\mathrm{SiN}$ and then subsequently growing the $\mathrm{GaN}$ layers for device applications. Keen interest was shown in the area of low-dimensional structures, namely, quantum dots and wires. Carrier relaxation in quantum dots was addressed, and its application in inter-subband detectors and lasers was discussed. K. Ploog (Paul Drude Institute, Berlin) elucidated the potential of engineering device structures by the epitaxial growth of large-mismatch materials. The maturity of quantum dots in realizing vertical-cavity surface-emitting lasers in the $1.3-\mu \mathrm{m}$ wavelength range was discussed. On the electronics front, the dominance of heterojunction bipolar transistor devices in mobile phones and microwave communications systems was stressed, and results on incorporating $\mathrm{SiGe}$ and III-V-based materials were presented. The potential of new piezoelectric crystals with very large coupling coefficients for future electronics applications was reviewed, along with the use of doped glasses for optical communications. Materials Science in Semiconductor Processing will publish the papers in a special issue.

Symposium O focused on Stress, Strain, and Structure-Property Relations in Thin Films. Topics within the symposium included defect interactions in metal and semiconductor thin films and strain-mediated systems; in situ studies of the growth, processing, and oxidation of materials; and advanced characterization techniques (electron, nuclear, and scanning-probe microscopies). The proceedings will be published in a special issue of Thin Solid Films.

In Symposium P: Superconducting Thin Films and Devices, many distinguished speakers, including P. Chu (Texas Center for Superconductivity at the University of Houston/Hong Kong University of Science and Technology) and C.C. Tsuei (IBM T.J. Watson Research Center), talked about the latest developments in the recently discovered medium- $T_{\mathrm{C}}$ superconductor $\mathrm{MgB}_{2}$ and $d$-wave superconductivity. The participants were happy to learn that this new material has great potential for technological impact since it can carry high supercurrents and the superconducting state can readily be achieved with conventional cryogenic coolers. Proceedings will be published in the international journal Superconductor Science and Technology.

IMRE and NUS were closely associated with the organization of ICMAT2001. The International Union of Materials Research Societies (IUMRS) endorsed the conference, and NUS, IMRE, the Economic Development Board (EDB), and the National Science and Technology Board (NSTB) generously sponsored the conference. The public lectures and Symposium B were also supported by NSTB and EDB, respectively. Other national and international organizations, including Nanyang Technological University, Singapore Exhibition \& Convention Bureau, Singapore Airlines, the U.S. Army Research Office-Far East, the French embassy in Singapore, and a large number of co-sponsors, supporters, exhibitors, and well-wishers spontaneously responded and gave encouragement and support by way of committing funds and help in kind.

B.V.R. CHOWDARI Chair, Organizing Committee, ICMAT2001; President, Materials Research Society-Singapore

\title{
MRS BULLETIN SEaKS IUMAS NEWS ON
}

\author{
- Upcoming Meetings \\ - Conference Reports \\ - Important Technical Developments \\ - Research News \\ - Policy Issues \\ MRS Bulletin, Materials Research Society \\ 506 Keystone Drive, Warrendale, PA 15086-7573 USA \\ E-mail: bulletin@mrs.org or gabrielle.long@nist.gov \\ Fax: 724-779-8313
}

